\title{
IMAGING
}

\section{Imaging the less seriously head injured child}

\author{
J F T Glasgow, S J McGovern
}

Each year, three and a half million children attend an accident and emergency department (A\&E), ${ }^{1}$ about $4 \%$ of whom have a head injury; hospital admission is required in approximately one tenth. ${ }^{2}$ Head injury accounts for $15 \%$ of deaths from 1-15 years of age and 25\% from $5-15$ years, ${ }^{3}$ and is arguably the principal public health challenge of childhood. Our aim is to define the terms of reference, emphasise dependence on an informed clinical approach, in order to identify those that require imaging as part of immediate management. Because a large proportion of patients attend out of hours and are seen by junior doctors, practice guidelines for $x$ ray examination (and/or hospital admission) have been developed. ${ }^{4}$ It is recognised, however, that these are widely ignored and skull radiographs, $2-9 \%$ of which show evidence of fracture, ${ }^{5}$ are used inappropriately as a triage tool.

Severity of head injury is impossible to define in absolute terms. Classifications of severity vary according to speciality group. ${ }^{4}$ Minor head injury is one where the causative mechanism is non-violent, full consciousness and recall have been retained throughout, and neurological features and vomiting are absent (table 1), as are clinical or radiographic evidence of skull fracture. Less serious head injury is therefore a diagnosis of exclusion. ${ }^{6}$ The clinical challenge is to use all available information to distinguish early the child in whom complications of brain injury are more likely, from the majority with superficial injury (table 1). Cogent radioprotective and financial evidence is detailed by the Royal College of Radiologists. $^{7}$

\section{History/mechanism of injury}

The central question to answer is whether there is evidence of brain injury, as opposed to superficial injury. History should focus on the mechanism of injury as a means of trying to understand the ergonomics and possible sequelae. Hospital notes often lack this clarity. Most injuries have a benign mechanism; however, falls from a height, road traffic accidents, or a suspicion of child abuse represent more serious injuries, or potentially so. Likewise, the high energy impact of for example, a golf club, golf ball, or motor vehicle dissipated over a small area greatly increases the chance of tissue damage - raising the possibility of brain injury or depressed fracture. Babies that roll off a sofa or bed have about a
$1 \%$ chance of sustaining a simple skull fracture $^{8}$; on the other hand, those with shaken-impact syndrome always have brain injury. ${ }^{9}$ Use of protective equipment (cycle helmet, seat belt) reduces the likelihood of brain injury. ${ }^{10}{ }^{11}$ Timing of the injury also should be known; in the ambulatory child, serious complications are very unlikely if six or more hours have elapsed. ${ }^{12}$ Information about life and health is essential, such as learning difficulties, a history of bleeding disorder, seizures, or regular use of medicine.

\section{Injury sequelae and early symptoms}

If all injuries were reliably witnessed, mechanisms might be clearer. The majority with minor injury have retained consciousness and been responsive throughout. In younger children, even this judgement can be problematic, and thorough assessment is said to be as difficult as in the intoxicated adult. ${ }^{4} \mathrm{~A}$ breath holding episode for example can confuse staff, and a report of extreme pallor, seizure activity, or period of confusion suggests injury that may be more than minor. Similarly, in older children or adolescents, complaints such as persistent headache unresponsive to simple analgesia, nausea, vomiting more than once, or seizure might suggest possible brain injury. The exception might be the child under two years of age who sustains minor injury within one hour of a meal; here vomiting is generally benign, and can be expected to settle within three hours. ${ }^{13}$

\section{Superficial injury or brain injury?}

This requires a general assessment of the child with emphasis on airway, breathing, and circulation followed by examination of both the nervous system, and of the head and scalp. In less serious head injury, the airway, breathing, and circulation will be normal. Neurological examination includes assessment of the level of consciousness as quantified by an age appropriate Glasgow Coma Score, pupil size and reactivity, and limb power, tone, and coordination. Fundoscopy in the school aged child is often unhelpful, whereas the presence of retinal haemorrhages in infants suggests nonaccidental injury. Such occult trauma may mask life threatening injury and computed tomography (CT) of the head can be diagnostic. ${ }^{9}$ Moreover, skeletal survey will identify extracranial injuries in $30-70 \%$ of abused children with head injuries. ${ }^{9}$ 
Table 1 The two extremes of the continuum between "simple head injury" and "potential/actual brain injury"*

\begin{tabular}{|c|c|}
\hline Simple head injury & Brain injury \\
\hline Benign mechanism (wearing protection) & Violent mechanism (no protection) \\
\hline Consciousness/recall retained throughout; no amnesia & Loss of consciousness $>5 \mathrm{~min}$ \\
\hline Vomiting less than twice (see text) & Persistent vomiting \\
\hline Transient headache (responds to simple analgesia) & Persistent headache \\
\hline Superficial bruising or laceration; latter $<5 \mathrm{~cm}$ long & $\begin{array}{l}\text { Boggy swelling, excess scalp tenderness, } \\
\text { or more extensive laceration; signs of } \\
\text { basal skull fracture }\end{array}$ \\
\hline Neurol & Focal neurological signs \\
\hline Child protection concerns not 1 & Possible abuse (see comme \\
\hline Babies & Full anterior fontanelle \\
\hline Clinical features clear & Features vague \\
\hline Fall $<60 \mathrm{~cm}$ or to non-hard surface & Fall from $>60 \mathrm{~cm}$, etc \\
\hline Action & Action \\
\hline $\begin{array}{l}\text { Discharge with age appropriate head injury advice to } \\
\text { care of responsible adult with ready access to hospital }\end{array}$ & $\begin{array}{l}\text { Observe closely, liaise with neurosurgeons; } \\
\text { if shows signs of deterioration, CT early }\end{array}$ \\
\hline
\end{tabular}

The further towards the right hand column the clinical features are, the greater the risk of intracranial injury, and of the need for urgent CT scanning.

${ }^{\star}$ Modified from Report of a Working Party on the Management of Head Injuries. ${ }^{20}$

Examination of the scalp for localised injury is important, and wounds should be sought especially behind the hairline. Bruising with a yellow hue suggests that injury occurred at least 48 hours earlier. A boggy swelling, on the other hand, may not have appeared if presentation is very early - as is often the case. Boggy swelling or excessive tenderness on palpation may suggest an underlying fracture that tends to imply application of greater force. Lacerations should be gently explored in a good light with a gloved finger for evidence of a depressed fracture. Signs of basal skull fracture include CSF rhinorrhoea or otorrhoea, or bruising of the sclera or in the orbits (racoon eyes), to an eardrum, or behind the mastoid (Battle's sign). Anterior fontanelle tension is a guide to the presence of raised intracranial pressure in babies.

\section{Are any investigations appropriate?}

History and examination of the child is aimed at finding evidence of brain injury or potential brain injury (table 1). Where this is thought likely, CT scanning is the more appropriate investigation. Is it useful to know that there is a skull fracture? In the fully conscious child without fracture, the absolute risk is small ( 1 in 12559 ) but increases 80 -fold to 1 in 157 when bone injury is present. ${ }^{14}$ Questions have been raised, however, about the degree to which such data should influence decision making. A number of studies now suggest that it is possible to use imaging more selectively and provide safe management. Except when child abuse is suspected, knowing that a skull fracture is present adds little to the information derived from a careful clinical assessment. Lloyd outlined a two year study of 6000 unselective A\&E attenders with head injury. Among 64 children with skull fractures, but normal neurological findings, only two intracranial abnormalities were found at CT scan, compared to those with abnormal neurological signs in whom 16 of $77 \mathrm{CT}$ studies were abnormal. Sensitivities of the two markers differed strikingly - $65 \%$ for skull radiography, but $91 \%$ for the presence of neurological abnormalities. ${ }^{15}$ The sensitivities and negative predictive values ( $83 \%$ and $97 \%$ respectively) indicate that brain injury commonly occurs in the absence of skull fracture, but is rare in the absence of neurological abnormalities.

A US study of 322 children with more severe head injuries found that intracranial injury was significantly linked to a history of loss of consciousness of more than five minutes, signs of basal fracture, altered mental status, focal neurological abnormalities, or the presence on $x$ ray of skull fracture. On the other hand, less specific features such as amnesia, headache, or vomiting, a briefer period of unconsciousness (less than five minutes), occurrence of seizure, or the presence of scalp wounds were insignificant predictors. Multivariate analysis identified focal neurological signs, seizure, or $x$ ray evidence of fracture as independent predictors of intracranial injury; however, if the radiographic evidence was omitted ( $x$ ray not done), an altered level of consciousness, focal neurological signs, or clinical evidence of basal fracture remained as independent predictors. ${ }^{16}$ Likewise, only $4 \%$ of children with parietal fractures and intracranial lesions on CT did not have such neurological features. ${ }^{17}$ These findings and those of others confirm that an injury severe enough to injure the skull is more likely also to injure the brain, than one not causing bony injury. ${ }^{15} 18$ However, it is not detection of a fracture that is crucial but the finding of neurological signs that identifies those requiring hospital observation and/or urgent investigation.

Too great an emphasis on seeking the presence of a skull fracture also carries the risk of overlooking serious intracranial injury in the absence of fracture. ${ }^{15}$ It is a particular problem in children. ${ }^{14}{ }^{17}$ This was highlighted in a radiological study of 1200 head injuries, where skull fracture was absent in $80 \%$ of those who developed intracranial haematomas, and in $85 \%$ of those with subdural collections. These proportions were even larger in babies and toddlers. The presence of neurological signs was emphasised in that subdural bleeding was half as frequent in those with a fracture as in those without; the presence of skull fracture merely served to confirm that a force had been applied to the head. ${ }^{19}$ Likewise, Teasdale found that in $55 \%$ of 69 children with an intracranial haematoma skull fracture was absent ${ }^{14}$; and in the shaken-impact syndrome, extensive thin collections of blood are seen on CT, especially within the interhemispheric fissure in the absence of fracture. ${ }^{9}$

\section{Are there good reasons not to irradiate?} Current guidelines on the indications for skull $x$ ray are broad, can be difficult to apply, and often require interpretation..$^{20} \mathrm{~A}$ poorly understood mechanism of injury, confusion about immediate sequelae or their relevance, especially in younger patients, results in large numbers of children being radiographed and/or admitted to hospital. Within the recognised limitations, greater emphasis is needed on a clinical approach to identify those at risk of complications, who actually require CT scanning rather than plain $x$ rays; only one study has shown a correlation between the presence of intracranial injury and the actual morphology 
of the fracture. ${ }^{17}$ For the huge majority with less serious injury, a better rationale might be to focus on those that do not require an $x$ ray (see table 1)-rather than the reverse. Investigation of non-specific symptoms-transient headache, drowsiness, or minimal vomiting (see above) - and/or the presence of modest scalp or facial injuries is not indicated. One small study of head injured children in Leeds used US criteria for not obtaining a skull $x$ ray to show the degree to which over investigation is carried out. By applying such criteria only $18 \%$ would have had radiographs, but this would have included all of the fractures. ${ }^{21}$

CT scanning is increasingly being used as the first and only investigation to confidently exclude (cranial and) intracranial injury. ${ }^{7}$ In the Liverpool study, intracranial abnormalities were not found in $85 \%$ of those scanned ${ }^{15}$; others quote a similar figure. ${ }^{22}$ Conversely, more than nine of ten with intracranial abnormalities had neurological features and would have had CT-even without skull radiography. ${ }^{15}$ Where symptoms persist beyond six hours, ${ }^{12}$ careful observation is needed and if progressive, immediate CT scanning. Apart from children in whom child protection is questioned, ${ }^{7}$ skull $x$ rays have little to contribute.

\section{Induction, training, audit}

About half of all skull radiographs after head injury are unnecessary. ${ }^{23}$ Best practice guidance should be part of the induction of new staff, ${ }^{7}$ but should be set in context (see table 1). Practitioners requesting $x$ rays might be asked to document the indication(s) for so doing. Persuading doctors on full shift rostas to follow practice guidelines is a challenge. Educational strategies using A\&E wall charts and consultant reinforcement, have succeeded in reducing skull $x$ rays by $35 \% .{ }^{24}$ As it is recommended that in future no child attend $A \& E$ at a centre that lacks inpatient paediatric facilities, paediatricians and A\&E specialists might prepare guidance jointly, thereby obviating ambiguity. ${ }^{1}$ This may be one of the tasks of the "designated liaison paediatrician". ${ }^{1}$ Finally, can non-radiology staff recognise the presence of a skull fracture? Apparently not very well as $23 \%$ were missed in Lloyd's series. ${ }^{15}$ Experience and training can improve the situation. ${ }^{25}$ Regular audit of radiology requests by front line staff, and of their interpretation will improve practice.

After head injury therefore, skull radiographs make little contribution to management. In the vast majority, a more considered history and examination can predict the likelihood of significant brain injury (table 1). Such patients should be observed in a unit with ready access to CT scanning and neurosurgical expertise. In light of recent research, joint guidelines need to be developed that focus more on when radiographs are not required. Senior staff must regularly review and reinforce good practice.

1 Royal College of Paediatrics \& Child Health. Accident \& emergency services for children: report of a multidisciplinary Child Health, 1999

2 Jennett B. Epidemiology of head injury. $\mathcal{F}$ Neurol Neurosurg Psychiatry 1996;60:362-9.

3 Sharples PM, Storey A, Aynsley-Green A, et al. Avoidable factors contributing to death of children with head injury. BMF 1990;300:87-91.

4 Swann IJ, McCarter DHA. Investigation of head injured patient. $\mathcal{F}$ Accid Emerg Med 1998;15:337-48.

patient. F Accid Emerg Med 1998;15:337-48.
5 Boulis ZF, Dick R. Head injuries in children-aetiology, symptoms, physical findings and X-ray wastage. Br f Radiol symptoms, phys

6 Beattie TF. Minor head injury. Arch Dis Child 1997;77:82-5.

7 The Royal College of Radiologists. Making the best use of a department of clinical radiology: guidelines for doctors, 4th ed. London: The Royal College of Radiologists, 1998.

8 Helfer RE, Sloris TL, Black M. Injuries resulting when small children fall out of bed. Pediatrics 1992;80:179-81.

9 Duhaime A-C, Christian CW, Rorke LB, Zimmerman RA. Nonaccidental head injury in infants-the shaken-baby syndrome. N Engl f Med 1998;338:1822-9.

10 Thompson RS, Rivara FP, Thompson DC. Case control study of the effectiveness of bicycle safety helmets. N Engl F Med 1998;320:1361-7.

11 Ruta D, Narayan V, Beattie TF. Prospective study of non-fatal childhood road traffic accidents: what can seat belt restraints achieve? Public Health Medicine 1993;15:8892 .

12 Sainsbury C, Sibert J. How long do we need to observe head injuries in hospital? Arch Dis Child 1984;59:856-9.

13 Hugenholtz H, Izukawa, Shear P, et al. Vomiting in children following head injury. Childs Nerv Syst 1987;3:266-70.

14 Teasdale GM. Head injury. BMF 1990;300:363-7.

5 Lloyd DA. Skull radiographs and children with blunt head injuries. Br f Surg 1998;85:580-1.

16 Quayle KS, Jaffe DM, Kuppermann N, et al. Diagnostic testing for acute head injury in children: when are head computed tomography and skull radiographs indicated? Pediatrics 1997;99:11-17.

17 Bonadio WA, Smith DS, Hillman S. Clinical indicators of intracranial lesion on computed tomographic scan in children with parietal skull fracture. Am F Dis Child 1989;143: 194-6.

18 Gordano U, Serracchioli A, Servadei F, Donati R, Piazza G. Intracranial lesions of surgical interest in minor head injuChilds Nerv Syst 1992;8:136-8.

19 Harwood-Nash DC, Hendrick EB, Hudson AR. The significance of skull fractures in children. Radiology 1971;101:151-6.

20 Royal College of Surgeons of England. Report of a Working Party on the Management of Head Injuries. London: Royal College of Surgeons of England, 1999.

21 Moreea S, Jones S, Zoltie N. Radiography for head trauma in children: what guidelines should we use? F Accid Emerg Med 1997;14:13-15.

22 Ramundo ML, McKnight T, Kempf J, Satkowiak L. Clinical predictors of computed tomographic abnormalities followng pediatric traumatic brain injury. Pediatr Emerg Care 1995;11:1-4.

23 Bell RE, Loop JW. The utility and futility of radiographic skull examination and trauma. N Engl f Med 1971;284: 236.

24 McNally E, de Lacey G, Lovell P, Wlch T. Posters for accident departments: simple method of sustaining reduction in x-ray examinations. BMF 1995;310:640-6.

25 Gleadhill DNS, Thomson JY, Simms P. Can more efficient use be made of $x$-ray examinations in the accident $\&$ emergency department? Injury 1987;294:943-7. 